\begin{tabular}{l}
\hline The Open Ophthalmology Journal \\
Bentham OPEN
\end{tabular}

RESEARCH ARTICLE

\title{
Reproducibility of Central Corneal Thickness Measurements in Normal Eyes Using the Zeiss Cirrus 5000 HD-OCT and Pentacam HR
}

Elmira Baghdasaryan ${ }^{1}$, Xiwen Huang ${ }^{1}$, Kenneth M. Marion ${ }^{1}$, Tudor C. Tepelus ${ }^{1}$, Homayoun Bagherinia $^{3}$, SriniVas R. Sadda ${ }^{1,2}$ and Hugo Y. Hsu ${ }^{1,2, *}$

${ }^{I}$ Doheny Eye Institute, Los Angeles, CA, USA

${ }^{2}$ Department of Ophthalmology, David Geffen School of Medicine, UCLA, Los Angeles, CA, USA

${ }^{3}$ Carl Zeiss Meditec, Inc., Dublin, CA, USA

Received: January 15, 2018

Revised: March 20, 2018

Accepted: April 23, 2018

Abstract:

\section{Objectives:}

To determine the repeatability and reproducibility of Central Corneal Thickness (CCT) measurements using two different anterior segment imaging modalities, including those obtained with the new anterior segment lens attachments for the Cirrus 5000 HD-OCT.

\section{Methods:}

A total of 32 eyes from 16 normal volunteers ( 8 male, 8 female) were enrolled in this prospective study. CCT was measured by the same examiner using the Cirrus 5000 HD-OCT and Pentacam HR. The results of CCT obtained by each method were averaged and compared using t-test analysis. The agreement between the measurement methods was evaluated. Coefficient of Repeatability (CoR) and Intra-Class Correlation Coefficient (ICC) were computed.

\section{Results:}

The mean measurements taken with the Cirrus OCT anterior chamber lens $\left(\mathrm{CCT}_{\mathrm{AC}}\right), \mathrm{HD}$ cornea lens $\left(\mathrm{CCT}_{\mathrm{HDC}}\right)$ and pachymetry scans $\left(\mathrm{CCT}_{\text {Pach }}\right)$ were $545.35 \pm 31.02,537.87 \pm 26.82$, and $532.04 \pm 29.82 \mu \mathrm{m}$, respectively. The mean CCT obtained with the Pentacam $\left(\mathrm{CCT}_{\text {Pent }}\right)$ was $545.51 \pm 30.71 \mu \mathrm{m} . \mathrm{CCT}_{\text {Pent }}$ were significantly higher than $\mathrm{CCT}_{\mathrm{HDC}}$ and $\mathrm{CCT}_{\text {Pach }}(p<0.0001)$. In contrast, the $\mathrm{CCT}_{\text {Pent }}$ and $\mathrm{CCT}_{\mathrm{AC}}$ were similar $(p=0.87)$. CCT, as evaluated by the two different instruments, showed excellent correlation $(r>0.98, p<$ $0.0001)$ with an ICC $>0.99$ (95\% CI, $0.97-0.99)$. CoR was the highest for $\mathrm{CCT}_{\text {Pach }}(3.7 \pm 1.4,95 \% \mathrm{CI}(3.0-4.6))$.

\section{Conclusion:}

CCT measurements from the Cirrus OCT using the new anterior segment lens attachments and the Pentacam HR are highly correlated. This should allow the use of a standardized correction factor if necessary to inter-relate the measurements between the two devices.

Keywords: Cornea, Central corneal thickness, Imaging, Optical coherency tomography, Pachymetry, Scheimpflug technology.

\section{INTRODUCTION}

Accurate measurement of Central Corneal Thickness (CCT) is critical for diagnosing corneal diseases, such as keratoconus and Fuchs Endothelial Corneal Dystrophy (FECD), as well as for monitoring corneal endothelial cell function [1 - 3]. Evaluation of CCT is also an essential parameter for refractive surgery in order to mitigate the possibility of iatrogenic corneal ectasia development [4]. CCT analysis is also useful for accurate glaucoma diagnosis

\footnotetext{
* Address correspondence to this author at the Doheny Eye Center of UCLA, Department of Ophthalmology, David Geffen School of Medicine at UCLA, 800 Fairmount Avenue, Suite 215, Pasadena, CA 91105, USA, Tel: 6268174701, Fax: 6268174702; Email: hhsu@doheny.org
} 
and management, as it is well known that there is a $0.35-0.38 \mathrm{~mm} \mathrm{Hg}$ increase in intraocular pressure (IOP) for every 10 $\mu \mathrm{m}$ increase in CCT [5 - 9]. With the introduction of the collagen cross-linking treatment for keratoconus, the evaluation of CCT has gained further importance as values higher than $400 \mu \mathrm{m}$ after epithelial debridement are deemed essential for protecting the corneal endothelium from the deleterious effects of ultraviolet-A radiation [10]. CCT evaluation has also been used as a parameter for corneal morphology assessment in contact lens wearers [11].

Both contact and non-contact devices using different techniques or strategies for assessment are currently available to clinicians for CCT estimation. An understanding of the underlying principles for a specific imaging technology is essential for accurate data interpretation, especially since non-contact CCT measurement devices are potentially more practical to employ in a busy clinical practice.

Ultrasonic Pachymetry (USP) is a contact method and has been traditionally regarded as the gold standard for CCT evaluation [12 - 15]. The contact nature of the USP method introduces patient discomfort and may increase the risk of infection and corneal epithelial damage. The USP approach also has several potential pitfalls which could result in erroneous diagnoses. Foremost, the reliability of USP depends on operator skill and technique, including the requirement for perpendicular placement of the probe with respect to the cornea [16]. Misinterpretation of the results can also occur after instillation of topical anesthesia which produces epithelial edema and CCT overestimation [17]. Also, displacement of the tear film with the probe has been shown to result in CCT underestimation; therefore, noncontact methods have become preferable in current clinic practices [18].

Current non-contact technologies for CCT evaluation include specular microscopy, scanning slit-beam topography, Scheimpflug technology-based cameras, and Optical Coherence Tomography (OCT). These imaging techniques have several advantages in addition to their non-contact nature of application: ease of use, high-resolution imaging, mapping functions, and comparability/correlation with the gold standard USP [19, 20].

Fewer studies, however, have evaluated the accuracy and repeatability of different CCT measurement methods [12, 20, 21]. The Pentacam HR (Oculus, Wetzlar, Germany) is a non-contact rotating Scheimpflug technology that has been shown to be repeatable and reproducible for CCT measurements [19, 22, 23]. Schiempflug based systems use rotating cameras and reconstruct the three-dimensional structure of the cornea from two-dimensional optical sections, which provide sharp images with detailed analysis from the anterior corneal surface through to the posterior aspect of the crystalline lens [24]. The Pentacam (Oculus Inc.), one of the commercially available Schiempflug instruments, is available in three models: Basic, Classic and High Resolution (HR). This system integrates two digital cameras for both the pupil tracking and image capture from the anterior segment. The HR rotating Scheimpflug technology used by the Pentacam allows cross-sectional imaging of the cornea by a 1.45 megapixel camera that rotates along the optical axis from 0 to 360 degrees and records 138.000 true elevation points within seconds. It uses a $475 \mathrm{~nm}$ wavelength blue LightEmitting Diode (LED) to provide anterior and posterior surface topography of the cornea, pachymetry, anterior chamber angle, depth and volume data as well as crystalline lens analysis (densitometry). The instrument-based software allows automatic analysis of various anterior segment parameters and takes 25 images per measurement within 2 seconds.

In contrast, the Zeiss Cirrus 5000 HD-OCT (Carl Zeiss Meditec, Dublin, CA, USA) is based on Spectral Domain(SD) OCT technology that uses coherence inferometry and measures the delay of back-reflected light. The device takes up 27,000 A-scans per second and has an axial resolution of $5 \mu \mathrm{m}$ [25]. It evaluates both retinal and anterior segment structures. SD OCT operates 65 times faster than its predecessor Time Domain (TD) OCT devices. Two external Anterior Segment (AS) lenses (cornea and anterior chamber) have recently become available to facilitate measurement of CCT, irido-corneal angles, angle-to-angle distances, anterior chamber dimensions, and crystalline lens vault. There are few studies, however, comparing CCT measurements obtained by these two different non-contact devices [26 - 28], particularly since the introduction of these new AS-OCT lenses, which have not been validated yet.

In this study, we take CCT measurements from the Zeiss OCT with the new AS lenses and compare them with a Scheimpflug camera to determine the repeatability and reproducibility of the OCT CCT measurements. To the best of our knowledge, this is the first study to evaluate these new AS lenses and to compare them with the results from a Scheimpflug camera.

\section{MATERIALS AND METHODS}

This prospective study was conducted at the Doheny Eye Center of UCLA in Pasadena, California. The study was approved by the Institutional Review Board of the University of California Los Angeles and conducted in accordance with the ethical standards stated in the Declaration of Helsinki and in compliance with the regulations set forth by the 
Health Insurance Portability and Accountability Act. Written informed consent was obtained from all subjects. All the participants were volunteers from the Doheny Eye Institute, who had recent eye exams establishing their eligibility for this study.

The exclusion criteria included: age $<18$ years, active ocular pathology, corneal pathology, any history of ocular surgery or trauma, recent contact lens wear (within 1 month), systemic diseases with ocular involvement, and astigmatism $>2$ Diopters (D). CCT readings were obtained from both eyes for each volunteer using the Zeiss Cirrus 5000 HD-OCT (Carl Zeiss Meditec, Dublin, CA, USA) with two AS lenses (Anterior Chamber (AC) and cornea) and the Pentacam HR (Oculus, Wetzlar, Germany) instruments. The sequence of measurements with the Pentacam HR and the Zeiss Cirrus HD-OCT was randomly chosen. All measurements were taken by a single examiner after 14:00 to minimize the effect of diurnal variations on CCT readings [29]. No topical anesthesia or lubricating eye drops were used in this study. For optimal scan quality, the volunteers were asked to blink twice before each measurement to form a smooth tear film on the cornea. Two CCT measurements were obtained for each study eye per scan type and recorded for subsequent statistical analyses.

\subsection{Imaging Devices and Measurement Technique}

The Pentacam HR was employed to take 2 successive scans for each subject's eye by a single examiner in one session. There was a short break between acquisitions to eliminate measurement interdependence. Apex pachymetry readings were recorded, averaged and used for subsequent CCT analysis. Images were automatically taken as soon as the Schiempflug camera was centered on the corneal apex at the pupil plane. Before each measurement, subjects were instructed to blink to create an optically smooth tear film over the cornea, and then to hold their eyes open during the image acquisition process. All measurements taken from scans with an examination quality specification of "OK" were considered valid and used for statistical analyses (Fig. 1A).

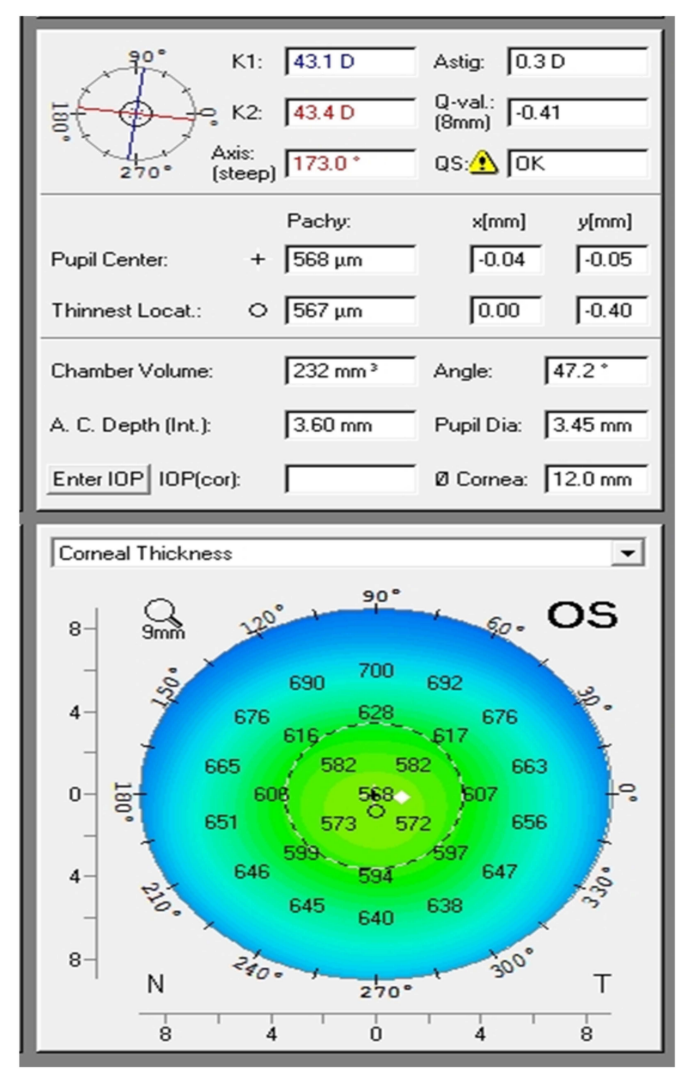

A

\begin{tabular}{|c|c|c|c|c|c|}
\hline $\begin{array}{c}\text { Range } \\
(\mathrm{mm})\end{array}$ & $\begin{array}{c}\text { Min. } \\
(\mu \mathrm{m})\end{array}$ & $\begin{array}{c}\text { Avg. } \\
(\mu \mathrm{m})\end{array}$ & $\begin{array}{c}\text { Max. } \\
(\mu \mathrm{m})\end{array}$ & $\begin{array}{c}\text { S-I } \\
(\mu \mathrm{m})\end{array}$ & $\begin{array}{c}\text { SN-IT } \\
(\mu \mathrm{m})\end{array}$ \\
\hline $0.0-2.0$ & 533 & 539 & 551 & - & - \\
\hline $2.0-5.0$ & 532 & 552 & 595 & 26 & 34 \\
\hline $5.0-7.0$ & 535 & 579 & 647 & 42 & 57 \\
\hline
\end{tabular}

\begin{tabular}{|c|c|c|c|}
\hline $\begin{array}{c}\text { Minimum } \\
\text { Thickness }(\mu \mathrm{m})\end{array}$ & 532 & $Y$ Min $(\mu \mathrm{m})$ & -898 \\
\hline $\begin{array}{c}\text { Pachy Min- } \\
\text { Median }(\mu \mathrm{m})\end{array}$ & -19 & $\begin{array}{c}\text { Central Corneal } \\
\text { Thickness }(\mu \mathrm{m})\end{array}$ & 537 \\
\hline
\end{tabular}

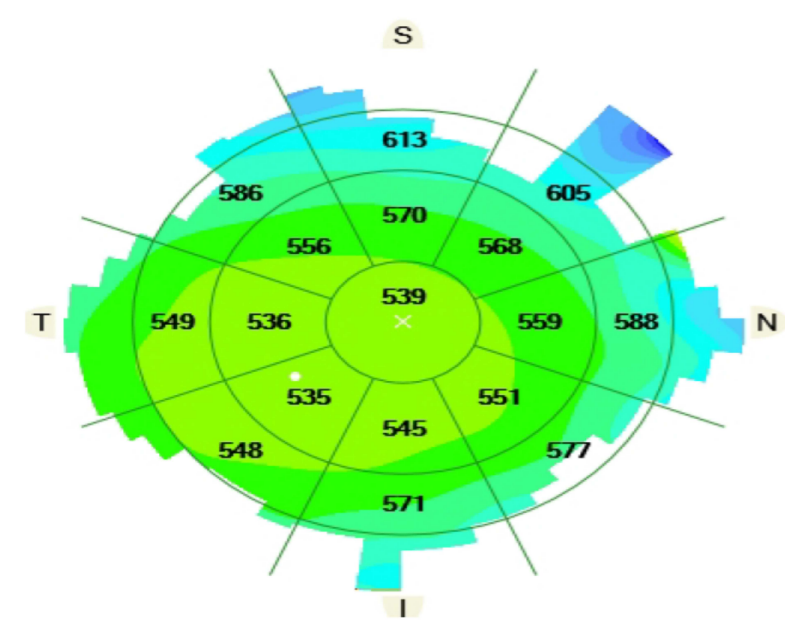

B

Fig. (1). Representative images of the Pentacam HR (A) and pachymetry scan reports derived from the Zeiss Cirrus HD-OCT (B). 
For the Zeiss Cirrus 5000 HD-OCT, high-resolution images were taken with both new external Cirrus AS lenses: the cornea-specific lens and the AC specific lens. The cornea lens attachment was used for the pachymetry map and HD cornea scans. The AC lens was used to obtain an AC scan. The Cirrus CCT was basically measured using both methods: manually with the help of the built-in calipers (HD cornea) and automated method (pachymetry map scan, AC scan). Each external lens was mounted on the OCT device with the help of a magnet for AS imaging. The HD cornea scan generates a single scan with a scan depth of $2 \mathrm{~mm}$ and a length of $9 \mathrm{~mm}$ as specified by the manufacturer. The caliper tool offered with the HD cornea scan was employed for manual measurement of the CCT Fig. (2B). It was placed on the central cornea corresponding to the hyper-reflective reflex seen on the scan (i.e. at the corneal apex), although it was challenging to place the tool precisely on the corneal apex in the hyper-reflective area.

The pachymetry scan consists of 24 radial B-scan lines (1024 samples per B-scan) with a scan depth of $2 \mathrm{~mm}$. A color-coded thickness map of the cornea was generated after image acquisition and CCT from 0-2 mm sector was selected for subsequent CCT analysis Fig. (1B). The thickness was defined as the distance from a point on the anterior corneal surface to the closest point on the posterior corneal surface. The pachymetry analysis tool provided automated cornea thickness measurement in seventeen sectors. Images were captured after the horizontal single scan line was placed on the corneal apex where the hyper-reflective corneal reflex was visible. Repeat scans were taken if the initial scan was decentered or had a poor corneal apex reflection.

The AC scans generated a wide-field image of the front of the eye at the depth of $5.8 \mathrm{~mm}$ with A scan length of 15 $\mathrm{mm}$ as shown in Fig. (2A). The image provides an overall view of the AC with bilateral irido-corneal angles in one glance. The manufacturer's software provides several automated measurements including CCT in $\mu \mathrm{m}$, angle-angle distance in $\mathrm{mm}, \mathrm{AC}$ depth in $\mathrm{mm}$, and lens vault in $\mu \mathrm{m}$.

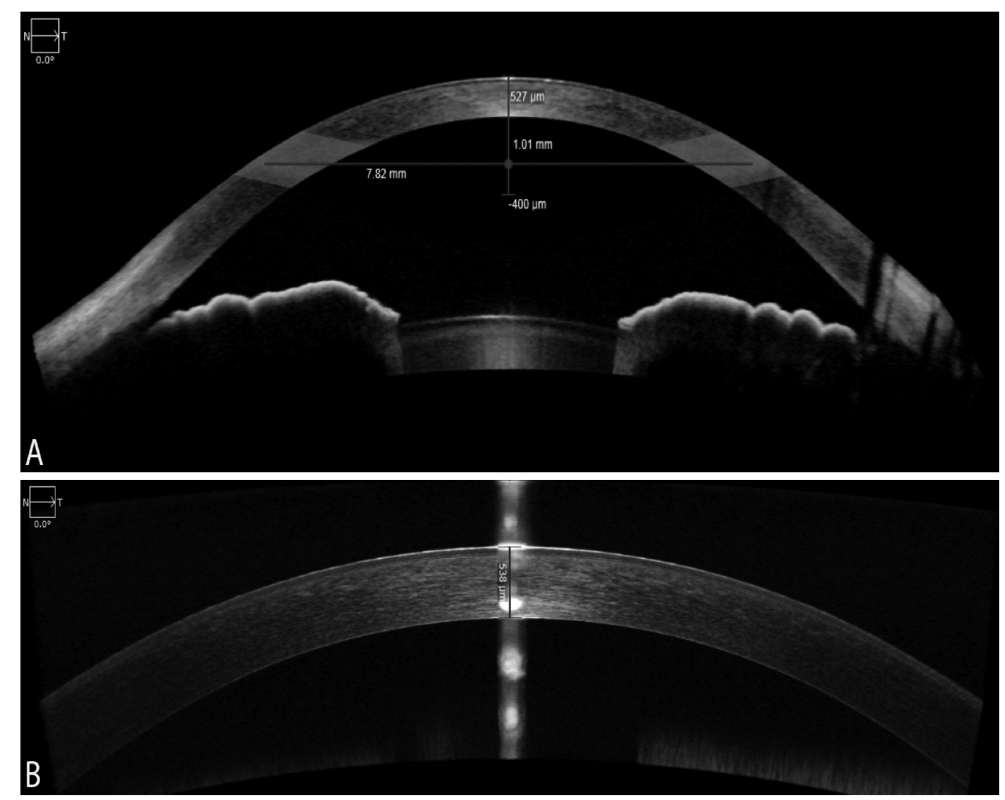

Fig. (2). AS-OCT image showing central corneal thickness measurement automated and manual methods by the Zeiss Cirrus OCT $\mathrm{AC}$ scan (A) and HD cornea scan (B), respectively.

\subsection{Statistical Analysis}

All datasets were checked for normal distribution using the Kolmogorov-Smirnov test and analyzed using the R Core Team [30]. Results are presented as the mean \pm Standard Deviation (SD). Paired $t$-tests were applied to compare CCT values obtained from the two different devices. The Pearson's correlation coefficient ( $r$ ) was used to determine the relationship between the measurements of the two instruments (values $>0.7$ indicating a strong positive correlation between 2 different devices). Linear regression was used to compare CCT measurements between the two different devices. Intra-operator repeatability was calculated with the two measurements obtained by the single examiner. Coefficient of Repeatability (CoR) and Intra-class Correlation Coefficients (ICC) were also calculated. The CoA was calculated as 1.96 times the standard deviation of the differences in the 2 measurements obtained for each of the two 
comparisons. The CoA is the value below which the difference between 2 measurements from 2 different devices can be expected to fall with $95 \%$ probability. The limits of agreement (LoA) were calculated as the mean difference between the two measurements \pm 1.96 times the standard deviation of the differences. Bland - Altman plots were used to assess the reliability of the measurements [31]. $P$ values $<0.05$ were considered statistically significant.

\section{RESULTS}

\subsection{Demographics}

A total of 32 eyes from 16 normal volunteers ( 8 male, 8 female) were enrolled. Their average age was $32.3 \pm 4.8$ years (range: $24-42$ years). The mean refractive error derived from the Pentacam HR was $0.7 \pm 0.4$ diopters (D).

\subsection{Central Corneal Thickness Measurements}

The mean CCT values measured by the Cirrus HD-OCT and Pentacam HR are shown in (Table 1).

Table 1. Mean \pm SD Values for CCT Measurements in Healthy Eyes Obtained by the Pentacam HR and Cirrus 5000 HDOCT.

\begin{tabular}{|c|c|c|c|c|}
\hline Parameter & $\begin{array}{c}\text { Cirrus } \\
\text { HD cornea }\end{array}$ & $\begin{array}{c}\text { Cirrus } \\
\text { AC scan }\end{array}$ & Cirrus Pachymetry scan & Pentacam HR \\
\hline CСТ $(\mu \mathrm{m})$ & $537.87 \pm 26.82$ & $545.35 \pm 31.02$ & $532.04 \pm 29.82$ & $545.51 \pm 30.71$ \\
\hline
\end{tabular}

Significant linear positive correlations were observed between the Cirrus HD-OCT and Pentacam HR CCT measurements (Pearson's correlation, $\mathrm{r}=$ 0.98 , p-value $<0.0001$ ) (Table 2).

Table 2. CCT Measurement Differences in Healthy Eyes Imaged by the Pentacam HR and Cirrus 5000 HD-OCT.

\begin{tabular}{|c|c|c|c|}
\hline- & $\begin{array}{c}C C T_{\text {Pent }} \text { Versus } \\
C C T_{\text {Pach }}\end{array}$ & $\begin{array}{c}C C T_{\text {Pent }} \text { Versus } \\
C C T_{A C}\end{array}$ & $\begin{array}{c}C C T_{\text {Pent }} \text { Versus } \\
C C T_{H D C}\end{array}$ \\
\hline $\begin{array}{c}\text { CCT }(\mu \mathrm{m}) \\
\text { Difference }^{1} \\
(\text { mean } \pm \text { SD })\end{array}$ & $13.46 \pm 4.9$ & $0.15 \pm 5.6$ & $7.6 \pm 6.2$ \\
\hline 95\% LoA & $3.86-23.08$ & $-10.84-11.15$ & $-4.51-19.78$ \\
\hline $95 \%$ CI & $11.70-15.23$ & $-1.86-2.17$ & $5.40-9.87$ \\
\hline$p$ value & $<0.0001$ & 0.87 & $<0.0001$ \\
\hline $\begin{array}{c}\text { Pearson Correlation ( } r \text {-value) } \\
\text { ( } p \text { - value) }\end{array}$ & $\begin{array}{c}0.987 \text { (CI 0.97-0.99) } \\
<0.0001\end{array}$ & $\begin{array}{c}0.983 \text { (CI 0.96-0.99) } \\
<0.0001\end{array}$ & $\begin{array}{c}0.985 \text { (CI 0.97-0.99) } \\
<0.0001\end{array}$ \\
\hline
\end{tabular}

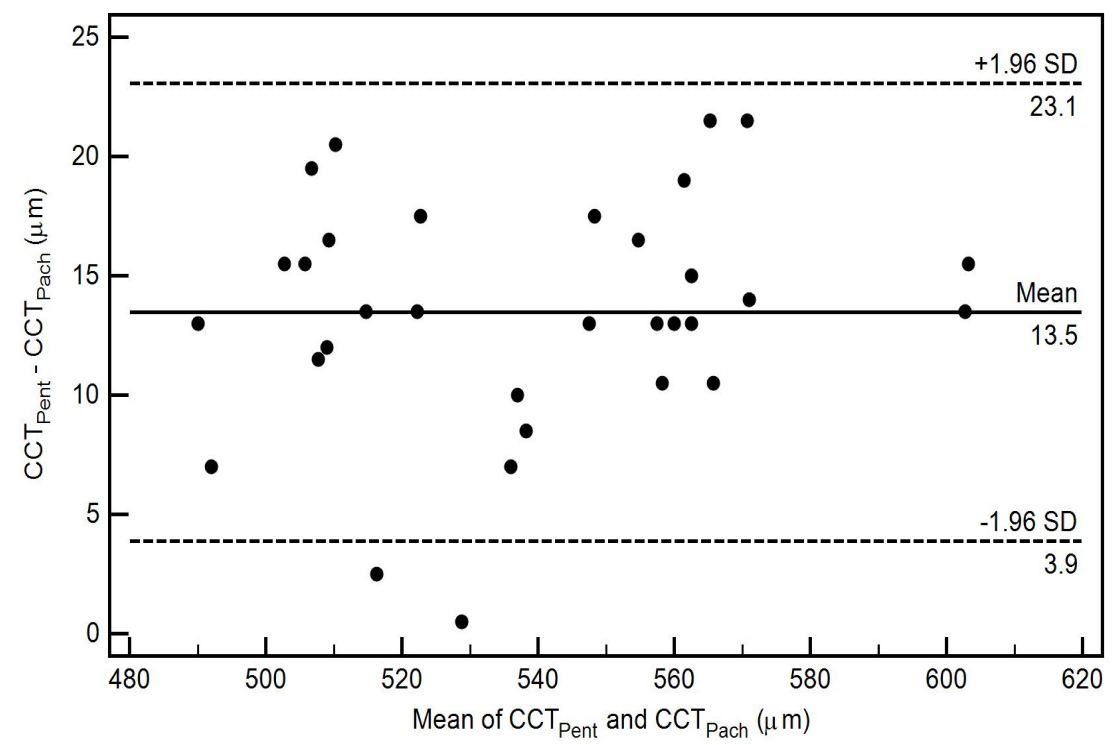

Fig. (3). Bland-Altman plot comparing $\mathrm{CCT}_{\mathrm{Pent}}$ and $\mathrm{CCT}_{\mathrm{Pach}}$. Mean value, lower and upper limits of agreement are indicated. The mean difference is represented by the solid line and the $95 \%$ confidence limits by the dotted lines. 
The pairwise comparisons of the CCT measurements using 3 different scan types of Cirrus HD-OCT with Pentacam HR in healthy eyes are also shown in Table 2. All pairwise comparisons demonstrated thinner CCT readings for the Cirrus HD-OCT, nevertheless there was no statistically significant difference between the CCT measurements from the Cirrus HD-OCT AC scan $\left(\mathrm{CCT}_{\mathrm{AC}}\right)$ and the Pentacam HR $\left(\mathrm{CCT}_{\text {Pent }}\right)(p$-value $=0.87)$ Table 2. The level of agreement between the two instruments for each scan type, as well as the mean of the difference between evaluations generated by the two instruments, is illustrated by the Bland-Altman plot (Figs. 3-5).

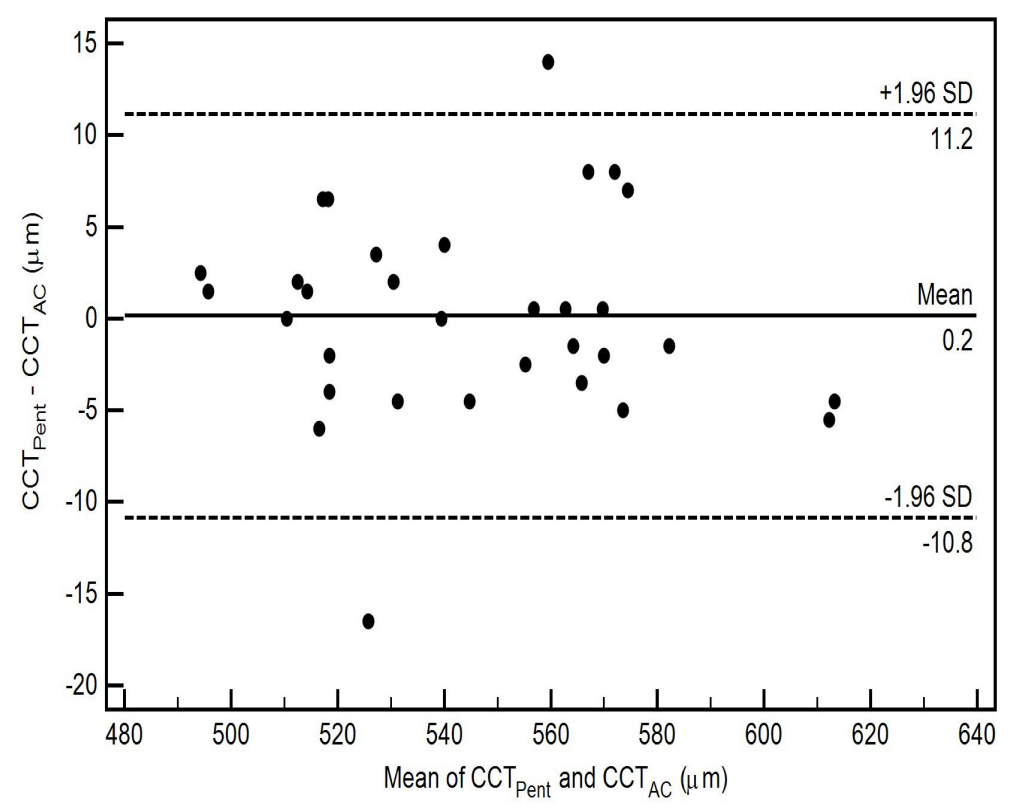

Fig. (4). Bland-Altman plot comparing $\mathrm{CCT}_{\mathrm{Pent}}$ and $\mathrm{CCT}_{\mathrm{AC}}$. Mean value, lower and upper limits of agreement are indicated. The mean difference is represented by the solid line and the $95 \%$ confidence limits by the dotted lines.

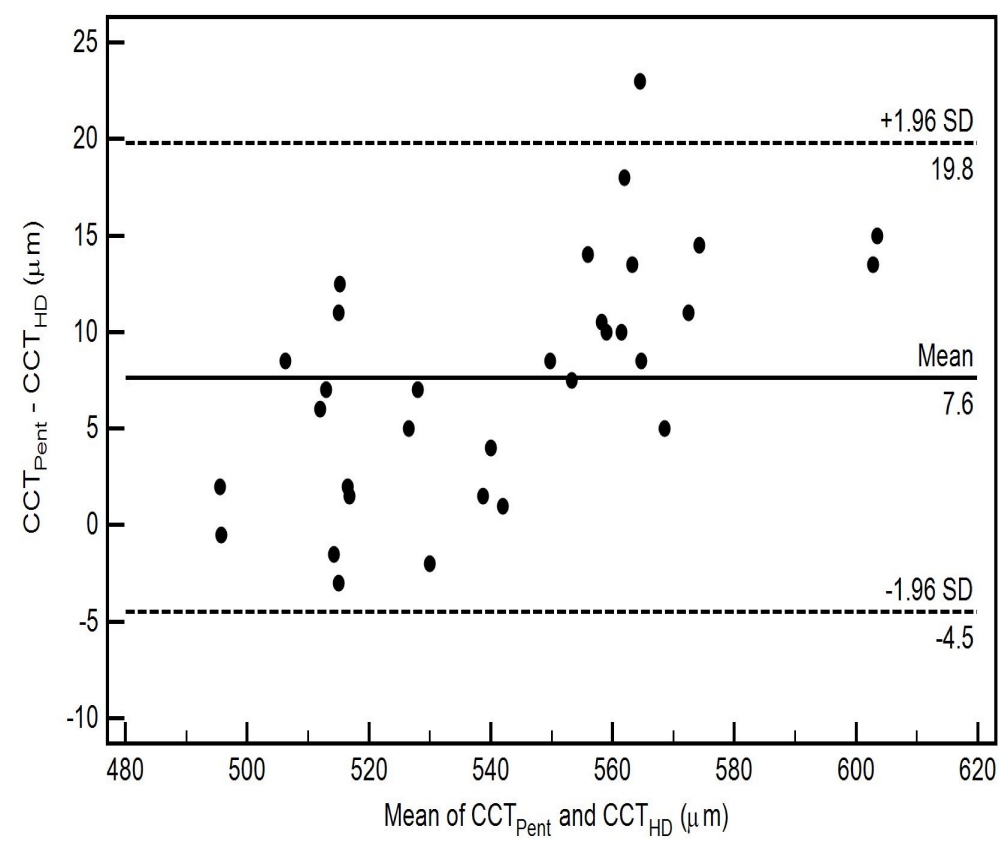

Fig. (5). Bland-Altman plot comparing $\mathrm{CCT}_{\mathrm{Pent}}$ and $\mathrm{CCT}_{\mathrm{HD}}$. Mean value, lower and upper limits of agreement are indicated. The mean difference is represented by the solid line and the $95 \%$ confidence limits by the dotted lines. 
The CoA for $\mathrm{CCT}_{\text {Pent }}$ and Cirrus HD-OCT pachymetry map scan $\left(\mathrm{CCT}_{\text {Pach }}\right), \mathrm{CCT}_{\text {Pent }}$ and $\mathrm{CCT}_{\mathrm{AC}}, \mathrm{CCT}_{\text {Pent }}$ and $\mathrm{Cirrus}$ HD-OCT HD cornea scan $\left(\mathrm{CCT}_{\mathrm{HDC}}\right)$ was 9.6, 11.0 and $12.1 \mu \mathrm{m}$, respectively. 95\% LoA for each pair are shown in Table 2. The magnitude of the LoA determines if two instruments can be used interchangeably as seen in Figs. (3-5). Linear regression analysis was used to evaluate the association of variables between devices. The slope of regression lines for $\mathrm{CCT}_{\text {Pach }}, \mathrm{CCT}_{\mathrm{AC}}$ and $\mathrm{CCT}_{\mathrm{HDC}}$ against $\mathrm{CCT}_{\text {Pent }}$ was $1.017,0.97$ and 1.129, respectively $(p<0.0001)($ Figs. 6-8).

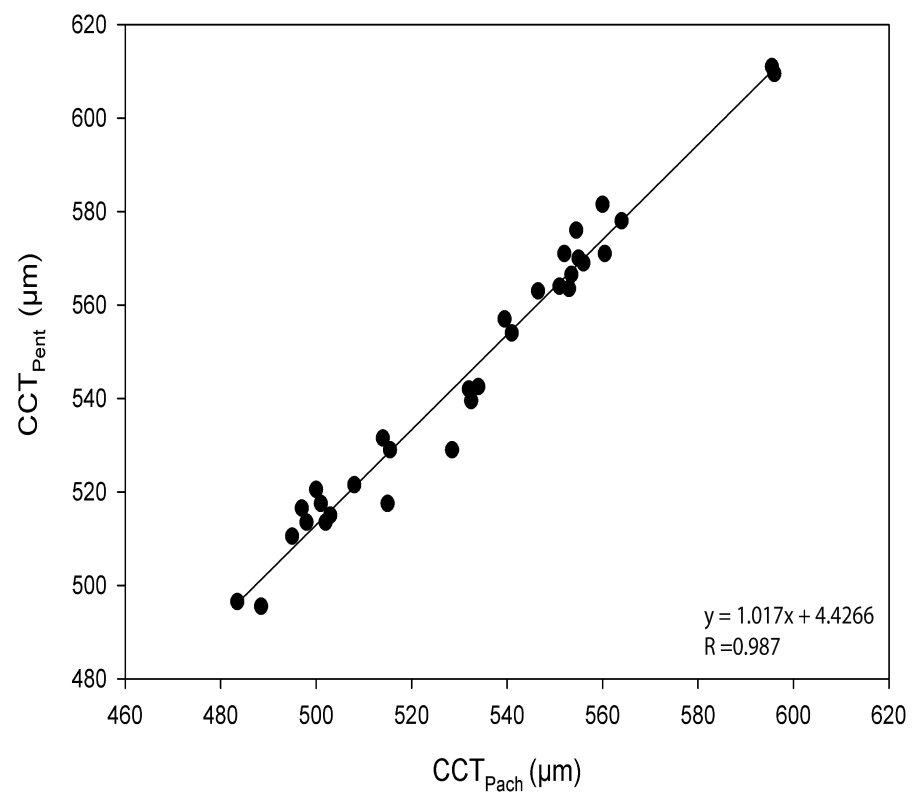

Fig. (6). Scatter plots between $\mathrm{CCT}_{\text {Pent }}$ and $\mathrm{CCT}_{\text {Pach }}$ measurements $(\mu \mathrm{m})$ showing a linear regression of $y=1.017 x+4.42$.

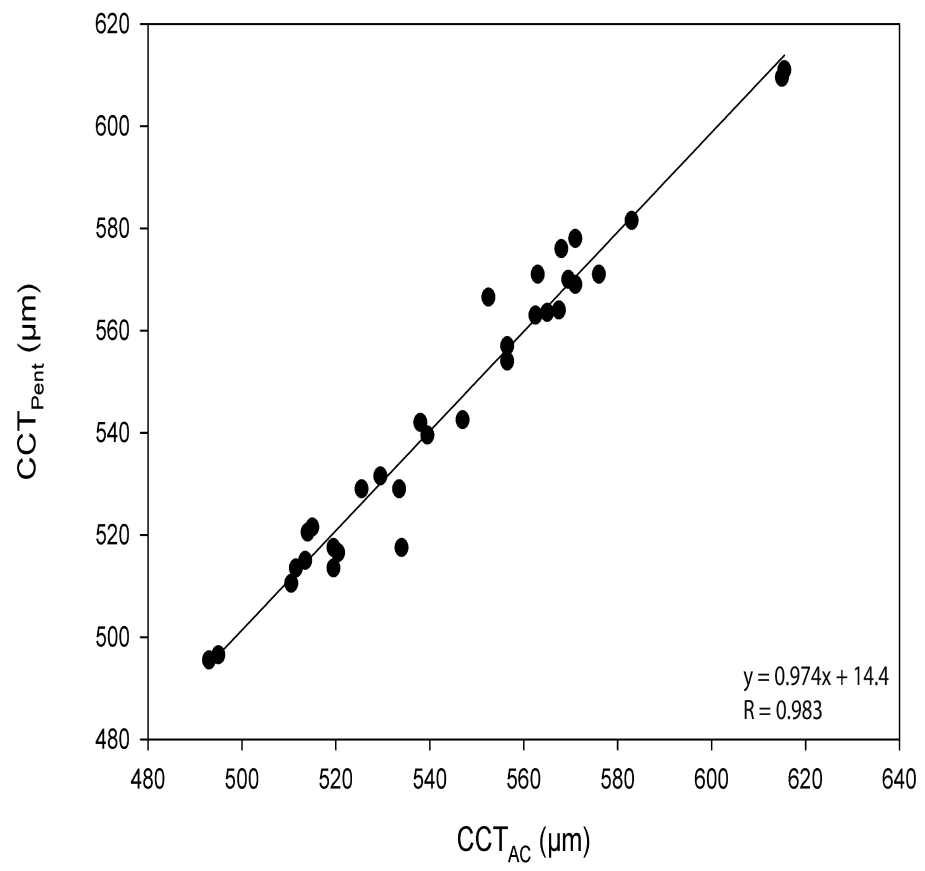

Fig. (7). Scatter plots between $\mathrm{CCT}_{\mathrm{Pent}}$ and $\mathrm{CCT}_{\mathrm{AC}}$ measurements $(\mu \mathrm{m})$ showing a linear regression of $y=0.97 x+14.42$. 


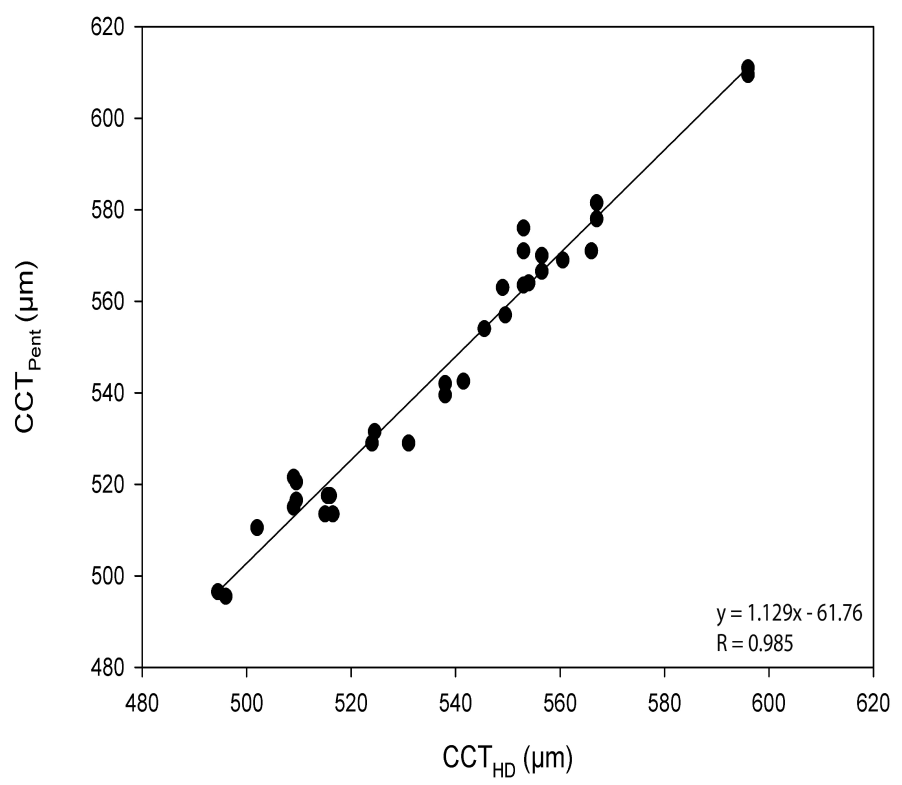

Fig. (8). Scatter plots between $\mathrm{CCT}_{\mathrm{Pent}}$ and $\mathrm{CCT}_{\mathrm{HD}}$ measurements $(\mu \mathrm{m})$ showing a linear regression of $y=1.129 x-61.76$.

Linear regression analysis, revealed the following relationships: $C C T_{\text {Pent }}=1.017 C C T_{\text {Pach }}+4.42 ; C C T_{\text {Pent }}=$ $0.97 C C T_{A C}+14.42$; and $C C T_{\text {Pent }}=1.129 C C T_{H D C}-61.76$. These equations can be used to predict the $C C T_{\text {Pent }}$ based on Cirrus HD-OCT measurements of CCT with the specific AS lenses (the cornea and AC). All CCT measurements showed excellent intra-operator repeatability (ICC $>0.99$ ) as shown in Table 2 . The CoR by a single observer was 3.8,12.8, 5.8 and 7.6 for $\mathrm{CCT}_{\text {Pach }}, \mathrm{CCT}_{\mathrm{AC}}, \mathrm{CCT}_{\mathrm{HDC}}, \mathrm{CCT}_{\text {Pent }}$, respectively.

\section{DISCUSSION}

In this study, we compared non-contact central corneal thickness measurements generated by OCT and Scheimpflug devices in order to assess the level of agreement and reproducibility. Repeatability itself refers to the variation in repeat measurements made on the same subject under identical conditions, meanwhile reproducibility refers to the variation in measurements made on a subject under changing conditions (e.g. different measurement methods or instruments being used). Establishing repeatability and reproducibility is critical for confident use of the measurements in clinical practice.

In the present study, we observed that the CCT measured by the Pentacam HR was thicker than that determined by the Cirrus 5000 HD-OCT in healthy eyes. Statistically significant differences were found between $\mathrm{CCT}_{\text {Pent }}$ and both the $\mathrm{CCT}_{\text {Pach }}$, and $\mathrm{CCT}_{\mathrm{HDC}}$, although the difference between $\mathrm{CCT}_{\text {Pent }}$ and $\mathrm{CCT}_{\mathrm{AC}}$ was not statistically insignificant. Although previous studies have compared OCT and Scheimpflug-derived CCT measurements [21, 26, 27, 32 - 35], to our knowledge, ours is the first to assess measurements obtained using the new external lenses for the Cirrus OCT.

Chen et al reported that Pentacam HR measurements of the CCT were on average $10.9 \mu \mathrm{m}$ greater than those obtained from RTVue-100 OCT (Optovue Inc., Fremont, CA, USA) [21]. According to the authors, that difference was small and comparable to the reported diurnal CCT fluctuation. The greatest average difference between the Pentacam HR and OCT CCT in our study was $13.5 \mu \mathrm{m}\left(\mathrm{CCT}_{\text {Pent }}-\mathrm{CCT}_{\text {Pach }}\right)$ Table 2, which was not higher than $5 \%$ of the mean CCT value for each imaging method Table 1. Also, the imaging time in our study was chosen accordingly to avoid possible diurnal CCT variation. Chen et al. also showed comparable reproducibility, high intra-observer repeatability and a high degree of correlation for both instruments. The authors recommended that the Pentacam HR and RTVue OCT can be used interchangeably for CCT measurements in healthy eyes [21].

Another study by Kanellopoulos et al. compared the HR Schiempflug camera Oculyzer 2 (Oculus, Wetzlar, Germany) with the RTVue-100 (Optovue Inc., Fremont, CA, USA) CCT values and found a $12.2 \mu \mathrm{m}$ statistically significant mean difference between the CCT measurements [36]. The authors suggested that the RTVue OCT appeared to report more accurate, but thinner CCT measurements, than the Oculyzer 2. We also observed that SD-OCT-derived measurements of CCT tended to be thinner than with the Schiempflug camera.

Another study by Ishibazawa et al. employed the RTVue-100 (Optovue Inc., Fremont, CA, USA) and Pentacam 
(Oculus, Wetzlar, Germany) to study the accuracy and repeatability of CCT measurements [27]. They also found a high degree of correlation between methods $(r=0.97$; $p$-value $<0.0001)$, as well as a high level of repeatability with all methods (ICC 0.97-0.98), similar to our study. With respect to the level of agreement in CCT measurements, they showed that the RTVue-100 underestimated the Pentacam CCT value with a mean difference of $22 \mu \mathrm{m}$, which was greater than the difference of $13.5 \mu \mathrm{m}$ found in our study. Similarly, Gonul et al. compared CCT measurements taken with the RTVue-100 (Optovue Inc., Fremont, CA, USA) and Schiempflug camera Sirius (CSO Inc., Firenze, Italy) [32]. Although the mean CCT differences between instruments were not statistically significant and CCT measurements were correlated, the measurements were not considered to be interchangeable in clinical practice because of the wide LoA values.

Yazici et al. measured CCT in healthy eyes using the Visante OCT (Carl Zeiss Meditec, Dublin, CA, USA) and Pentacam (Oculus, Wetzlar, Germany). Unlike for SD-OCT, this study showed that the mean CCT measured by the Visante was thinner than the Pentacam CCT values by $20.76 \mu \mathrm{m}(p$-value $<0.0001)$; measurements from the two methods, however, were correlated $(r=0.88)$ [33]. In our study, we observed a much higher level of correlation between methods with $r>0.98$ for all comparisons. Doors et al. also showed that the Pentacam significantly overestimated CCT compared to the Visante OCT, by a mean of $19.2 \mu \mathrm{m}$ [35]. The authors suggested that these devices should not be used interchangeably for CCT measurements in healthy eyes.

Kiraly et al. used Cirrus HD-OCT 5-line raster mode as well as Pentacam HR to estimate repeatability and comparability of the CCT measurements [34]. The mean difference between these methods was shown to be $11.44 \mu \mathrm{m}$, which was comparable to our maximum reported mean difference of $13.5 \mu \mathrm{m}$. Intra-examiner repeatability was high as it was in our study, but the level of agreement in CCT values between devices was insufficient to recommend that they can be used interchangeably, without instituting a correction factor.

The major difference between these previous studies and ours was the use of specialized external lenses for capturing the OCT data as well as the difference between wavelength in different OCT platforms used (Visante represents time domain OCT with $1310 \mathrm{~nm}$ wavelength). Perhaps the difference between the $\mathrm{CCT}_{\text {Pent }}$ and $\mathrm{CCT}_{\text {Pach }}$ could be due to the fact that the Pentacam is expressing a single point measurement, while pachymetry scan from AS-OCT is an average of the central $2 \mathrm{~mm}$ area in the cornea. In contrast to this, the measurements obtained by the AC and HD OCT were closer to those obtained with Pentacam as all of them are point measurements taken from the apex. Our findings demonstrated a high level of correlation between scans obtained with the different lenses and excellent intraobserver repeatability. Additionally, through our linear regression analysis, we could generate equations which could be used to convert the OCT-derived measurements of $\mathrm{CCT}_{\mathrm{HDC}}$ and $\mathrm{CCT}_{\mathrm{Pach}}$ to values one might expect from the Pentacam. Measurements taken with the $\mathrm{AC}$ lens $\left(\mathrm{CCT}_{\mathrm{AC}}\right)$ were similar to the Pentacam values and can be implemented without using a standardized correction factor.

\section{LIMITATIONS}

The limitation of our study is the lack of evaluation of the inter-examiner repeatability. Future studies are required to explore the precision of the CCT measurements in eyes after refractive surgery and keratoconus eyes before and after collagen cross-linking treatment.

\section{CONCLUSION}

In conclusion, Cirrus 5000 HD-OCT using cornea and anterior chamber lens attachments for anterior segment imaging and Pentacam HR can be used reliably by an experienced operator in clinical practice for CCT measurements in healthy eyes.

\section{ETHICS APPROVAL AND CONSENT TO PARTICIPATE}

This prospective study was conducted at the Doheny Eye Center of UCLA in Pasadena, California and was approved by the Institutional Review Board of the University of California Los Angeles.

\section{HUMAN AND ANIMAL RIGHTS}

No Animals were used in this research. All human research procedures followed were in accordance with the ethical standards of the committee responsible for human experimentation (institutional and national), and with the Helsinki Declaration of 1975, as revised in 2008 . 


\section{CONSENT FOR PUBLICATION}

Written informed consent was obtained from all subjects.

\section{CONFLICTS OF INTEREST}

The authors have the following financial disclosures:

Elmira Baghdasaryan, None; Xiwen Huang, None; Kenneth M. Marion, None; Tudor C. Tepelus, Homayoun Bagherinia, None; SiniVas R. Sadda, Carl Zeiss Meditec (F), Optos (F, C), Allergan (F, C), Genentech (F, C), Alcon (C), Novartis (C), Roche (C), Regeneron (C), Bayer (C), Thrombogenics (C), Stem Cells (C), Avalanche (C); Hugo Y. Hsu, None.

\section{ACKNOWLEDGEMENTS}

Funding: No funding or sponsorship was received for this study or publication of this article.

Authorship: All named authors meet the International Committee of Medical Journal Editors (ICMJE) criteria for authorship for this manuscript, take responsibility for the integrity of the work, and have given final approval to the version to be published.

\section{REFERENCES}

[1] Waring GO III, Bourne WM, Edelhauser HF, Kenyon KR. The corneal endothelium. Normal and pathologic structure and function. Ophthalmology 1982; 89(6): 531-90.http://www.ncbi.nlm.nih.gov/pubmed/7122038 [Internet]. [http://dx.doi.org/10.1016/S0161-6420(82)34746-6] [PMID: 7122038]

[2] Ambrósio R Jr, Alonso RS, Luz A, Coca Velarde LG. Corneal-thickness spatial profile and corneal-volume distribution: Tomographic indices to detect keratoconus. J Cataract Refract Surg 2006; 32(11): 1851-9. [http://dx.doi.org/10.1016/j.jcrs.2006.06.025] [PMID: 17081868]

[3] Kopplin LJ, Przepyszny K, Schmotzer B, et al. Relationship of Fuchs endothelial corneal dystrophy severity to central corneal thickness. Arch Ophthalmol (Chicago, Ill 1960) 2012; 130(4): 433-9. [http://dx.doi.org/10.1001/archopthalmol.2011.1626]

[4] Argento C, Cosentino MJ, Tytiun A, Rapetti G, Zarate J. Corneal ectasia after laser in situ keratomileusis. J Cataract Refract Surg 2001; 27(9): 1440-8. [http://dx.doi.org/10.1016/S0886-3350(01)00799-4] [PMID: 11566530]

[5] Gordon MO, Beiser JA, Brandt JD, et al. The ocular hypertension treatment study: Baseline factors that predict the onset of primary openangle glaucoma. Arch Ophthalmol 2002; 120(6): 714-20.

[http://dx.doi.org/10.1001/archopht.120.6.714] [PMID: 12049575]

[6] Brandt JD, Beiser JA, Gordon MO, Kass MA. Central corneal thickness and measured IOP response to topical ocular hypotensive medication in the Ocular Hypertension Treatment Study. Am J Ophthalmol 2004; 138(5): 717-22. [http://dx.doi.org/10.1016/j.ajo.2004.07.036] [PMID: 15531304]

[7] Randleman JB, Woodward M, Lynn MJ, Stulting RD. Risk assessment for ectasia after corneal refractive surgery. Ophthalmology 2008; 115(1): 37-50.http://www.ncbi.nlm.nih.gov/entrez/ query.fcgi?cmd=Retrieve\&db=PubMed\&dopt=Citation\&list_uids=17624434 [Internet]. [http://dx.doi.org/10.1016/j.ophtha.2007.03.073] [PMID: 17624434]

[8] Santhiago MR, Giacomin NT, Smadja D, Bechara SJ. Ectasia risk factors in refractive surgery. Clin Ophthalmol 2016; 10: 713-20. [http://dx.doi.org/10.2147/OPTH.S51313] [PMID: 27143849]

[9] Hoffmann EM, Lamparter J, Mirshahi A, et al. Distribution of central corneal thickness and its association with ocular parameters in a large central European cohort: The Gutenberg health study. PLoS One 2013; 8(8): e66158.

[http://dx.doi.org/10.1371/journal.pone.0066158] [PMID: 23936291]

[10] Ashwin PT, McDonnell PJ. Collagen cross-linkage: A comprehensive review and directions for future research. Br J Ophthalmol 2010; 94(8): 965-70. [Internet]. [http://dx.doi.org/10.1136/bjo.2009.164228] [PMID: 19666925]

[11] Martin R, de Juan V, Rodríguez G, Cuadrado R, Fernandez I. Measurement of corneal swelling variations without removal of the contact lens during extended wear. Invest Ophthalmol Vis Sci 2007; 48(7): 3043-50. [http://dx.doi.org/10.1167/iovs.06-1372] [PMID: 17591871]

[12] Miglior S, Albe E, Guareschi M, Mandelli G, Gomarasca S, Orzalesi N. Intraobserver and interobserver reproducibility in the evaluation of ultrasonic pachymetry measurements of central corneal thickness. Br J Ophthalmol 2004; 88(2): 174-7. [http://dx.doi.org/10.1136/bjo.2003.023416] [PMID: 14736765]

[13] Sadoughi MM, Einollahi B, Einollahi N, Rezaei J, Roshandel D, Feizi S. Measurement of central corneal thickness using ultrasound pachymetry and Orbscan II in normal eyes. J Ophthalmic Vis Res 2015; 10(1): 4-9. [http://dx.doi.org/10.4103/2008-322X.156084] [PMID: 26005545] 
[14] Gherghel D, Hosking SL, Mantry S, Banerjee S, Naroo SA, Shah S. Corneal pachymetry in normal and keratoconic eyes: Orbscan II versus ultrasound. J Cataract Refract Surg 2004; 30(6): 1272-7. [http://dx.doi.org/10.1016/j.jcrs.2003.11.049] [PMID: 15177603]

[15] Chakrabarti HS, Craig JP, Brahma A, Malik TY, McGhee CNJ. Comparison of corneal thickness measurements using ultrasound and Orbscan slit-scanning topography in normal and post-LASIK eyes. J Cataract Refract Surg 2001; 27(11): 1823-8. [http://dx.doi.org/10.1016/S0886-3350(01)01089-6] [PMID: 11709257]

[16] Salz JJ, Azen SP, Berstein J, Caroline P, Villasenor RA, Schanzlin DJ. Evaluation and comparison of sources of variability in the measurement of corneal thickness with ultrasonic and optical pachymeters. Ophthalmic Surg 1983; 14(9): 750-4. [PMID: 6646620]

[17] Nam SM, Lee HK, Kim EK, Seo KY. Comparison of corneal thickness after the instillation of topical anesthetics: proparacaine versus oxybuprocaine. Cornea 2006; 25(1): 51-4 [http://dx.doi.org/10.1097/01.ico.0000179929.97651.59] [PMID: 16331042]

[18] Nissen J, Hjortdal JO, Ehlers N, Frost-Larsen K, Sørensen T. A clinical comparison of optical and ultrasonic pachometry. Acta Ophthalmol (Copenh) 1991; 69(5): 659-63. [http://dx.doi.org/10.1111/j.1755-3768.1991.tb04857.x] [PMID: 1776423]

[19] Kim SW, Byun YJ, Kim EK, Kim TI. Central corneal thickness measurements in unoperated eyes and eyes after PRK for myopia using Pentacam, Orbscan II, and ultrasonic pachymetry. J Refract Surg 2007; 23(9): 888-94. [PMID: 18041241]

[20] Lázaro C, Hernández EM, Martínez D, Redondo P. Comparison of central corneal thickness measured with anterior segment optical coherence tomography versus ultrasonic pachymetry. Arch Soc Esp Oftalmol 2013; 88(2): 45-9.http://www.sciencedirect.com/ science/article/pii/ S0365669112002602 [Internet]. [PMID: 23433191]

[21] Chen S, Huang J, Wen D, Chen W, Huang D, Wang Q. Measurement of central corneal thickness by high-resolution Scheimpflug imaging, Fourier-domain optical coherence tomography and ultrasound pachymetry. Acta Ophthalmol 2012; 90(5): 449-55. [http://dx.doi.org/10.1111/j.1755-3768.2010.01947.x] [PMID: 20560892]

[22] Huang J, Ding X, Savini G, et al. A Comparison between Scheimpflug imaging and optical coherence tomography in measuring corneal thickness. Ophthalmology [Internet] 2013 ;120(10):1951-8 Available from: 2013.http://www.ncbi.nlm.nih.gov/ pubmed/23672973 Oct. [cited 2017 Apr. 6] [http://dx.doi.org/10.1016/j. ophtha.2013.02.022]

[23] Hernández-Camarena JC, Chirinos-Saldaña P, Navas A, et al. Repeatability, reproducibility, and agreement between three different Scheimpflug systems in measuring corneal and anterior segment biometry. J Refract Surg 2014; 30(9): 616-21.http://www.healio.com/ doiresolver?doi=10.3928/1081597X-20140815-02\%5Cnhttp://www.ncbi.nlm.nih.gov/pubmed/25250418 [Internet]. [http://dx.doi.org/10.3928/1081597X-20140815-02] [PMID: 25250418]

[24] Oliveira CM, Ribeiro C, Franco S. Corneal imaging with slit-scanning and Scheimpflug imaging techniques. Clin Exp Optom 2011; 94(1): 33-42. [http://dx.doi.org/10.1111/j.1444-0938.2010.00509.x] [PMID: 20718786]

[25] Huang D, Swanson EA, Lin CP, et al. Optical coherence tomography. Science 1991; 254(5035): 1178-81.http://www.sciencemag.org/ content $/ 254 / 5035 / 1178 \% 5 \mathrm{Cnhttp}$ [http://dx.doi.org/10.1126/science.1957169] [PMID: 1957169]

[26] Prospero Ponce CM, Rocha KM, Smith SD, Krueger RR. Central and peripheral corneal thickness measured with optical coherence tomography, Scheimpflug imaging, and ultrasound pachymetry in normal, keratoconus-suspect, and post-laser in situ keratomileusis eyes. J Cataract Refract Surg 2009; 35(6): 1055-62. [http://dx.doi.org/10.1016/j.jcrs.2009.01.022] [PMID: 19465292]

[27] Ishibazawa A, Igarashi S, Hanada K, et al. Central corneal thickness measurements with Fourier-domain optical coherence tomography versus ultrasonic pachymetry and rotating Scheimpflug camera. Cornea 2011; 30(6): 615-9. [http://dx.doi.org/10.1097/ICO.0b013e3181d00800] [PMID: 21282999]

[28] Randleman JB, Lynn MJ, Perez-Straziota CE, Weissman HM, Kim SW. Comparison of central and peripheral corneal thickness measurements with scanning-slit, Scheimpflug and Fourier-domain ocular coherence tomography. Br J Ophthalmol 2015; 99(9): 1176-81.http://www.ncbi.nlm.nih.gov/pubmed/25824260 [Internet]. [http://dx.doi.org/10.1136/bjophthalmol-2014-306340] [PMID: 25824260]

[29] du Toit R, Vega JA, Fonn D, Simpson T. Diurnal variation of corneal sensitivity and thickness. Cornea 2003; 22(3): 205-9.http://www.ncbi.nlm.nih.gov/pubmed/12658083 [Internet]. [http://dx.doi.org/10.1097/00003226-200304000-00004] [PMID: 12658083]

[30] R Core Team. Development Core Team [Internet]. R: A Language and Environment for Statistical Computing Available from: 2016; 55(3): 275-86.https://www.r-project.org/

[31] Bland JM, Altman DG. Statistical methods for assessing agreement between two methods of clinical measurement. Lancet 1986; 1(8476): 307-10.

[http://dx.doi.org/10.1016/S0140-6736(86)90837-8] [PMID: 2868172] 
[32] Gonul S, Koktekir BE, Bakbak B, Gedik S. Comparison of central corneal thickness measurements using optical low-coherence reflectometry, Fourier domain optical coherence tomography, and Scheimpflug camera. Arq Bras Oftalmol 2014; 77(6): 345-50.http://www.ncbi.nlm.nih.gov/pubmed/25627178 [Internet]. [PMID: 25627178]

[33] Yazici AT, Bozkurt E, Alagoz C, et al. Central corneal thickness, anterior chamber depth, and pupil diameter measurements using Visante OCT, Orbscan, and Pentacam. J Refract Surg 2010; 26(2): 127-33. [http://dx.doi.org/10.3928/1081597X-20100121-08] [PMID: 20163077]

[34] Kiraly L, Stange J, Kunert KS, Sel S. 2017.Repeatability and agreement of central corneal thickness and keratometry measurements between four different devices. $2017 \mathrm{~J}$ Ophthalmol [Internet] https:/www.hindawi.com/journals/joph/2017/6181405/ [cited 2017 Apr 11]; 2017 6181405

[35] Doors M, Cruysberg LPJ, Berendschot TTJM, de Brabander J, Verbakel F. 2009; Comparison of central corneal thickness and anterior chamber depth measurements using three imaging technologies in normal eyes and after phakic intraocular lens implantation. Available from: Graefes Arch Clin Exp Ophthalmol [Internet] 2009; 247(8): 1139-46.http://www.pubmedcentral. nih.gov/articlerender. fcgi?artid=2709228\&tool=pmcentrez\&rendertype $=$ abstract

[36] Kanellopoulos AJ, Asimellis G. Comparison of high-resolution Scheimpflug and high-frequency ultrasound biomicroscopy to anteriorsegment OCT corneal thickness measurements. Clin Ophthalmol 2013; 7: 2239-47. [http://dx.doi.org/10.2147/OPTH.S53718] [PMID: 24348011]

\section{(C) 2018 Baghdasaryan et al.}

This is an open access article distributed under the terms of the Creative Commons Attribution 4.0 International Public License (CC-BY 4.0), a copy of which is available at: (https://creativecommons.org/licenses/by/4.0/legalcode). This license permits unrestricted use, distribution, and reproduction in any medium, provided the original author and source are credited. 